\title{
Narradores y subnarradores en el audiovisual. La voz narrativa en el informativo de televisión
}

\author{
Cristóbal RUITIÑA TESTA \\ ESNE - Universidad Camilo José Cela \\ ruitinna@gmail.com
}

Recibido: 22/07/2011

Aceptado: 12/12/2011

\begin{abstract}
Resumen
Este artículo es una aportación al análisis de la voz narrativa en un discurso audiovisual de origen periodístico: el informativo de televisión. El autor ha procedido a una lectura narratológica de las diferentes instancias enunciadoras detectables en el formato. La multiplicidad de voces narrativas explica en gran parte una de sus características esenciales: la fragmentación. Asimismo, el texto constata que esta multiplicidad no es arbitraria, sino que responde a la vocación de veracidad que alienta en todo discurso periodístico.
\end{abstract}

Palabras clave: Narrativa, audiovisual, televisión, narratología

\section{Narrators and Subnarrators in the Audio-Visual One The Narrative Voice in the News Program One}

\begin{abstract}
This article is a contribution to the analysis of the narrative voice in an audio-visual speech of journalistic origin: the news program one. The author has done a narratologic reading from the different detectable instances of the statement in the format. The multiplicity of narrative voices explains largely one of his essential characteristics: the fragmentation. Likewise, the text states that this multiplicity is not arbitrary, but it answers to the vocation of veracity that it encourages in any journalistic speech.

Keywords: Narrative, Audio-Visual, Television, Narratology

\section{Referencia normalizada}

RUITIÑA TESTA, Cristóbal (2012): "Narradores y subnarradores en el audiovisual. La voz narrativa en el informativo de televisión". Estudios sobre el mensaje periodístico. Vol. 18, núm. 1, págs.: 371-381. Madrid, Servicio de Publicaciones de la Universidad Complutense.
\end{abstract}

Sumario: 1. Introducción: la perspectiva narratológica en la narración audiovisual. 2. Metodología y objeto del análisis. 3. La voz narrativa. 4. Conclusiones. 5. Referencias bibliográficas.

\section{Introducción: la perspectiva narratológica en la narración audiovisual}

La comparación periodístico-literaria a la que ha procedido la tesis doctoral de la que proceden los aspectos tratados en este artículo se ha centrado principalmente en las cuestiones morfológicas del texto. La Literatura Comparada permite estudiar las relaciones puramente intraliterarias que se dan entre dos textos, pero también las interliterarias, aquellas entendidas como las propias de dos textos dados no estrictamente literarios, pero sí lingüísticos. Esta última es, precisamente, la fundamentación teórica sobre la que descansa el análisis pionero de CHILLÓN (1994) sobre el género periodístico del reportaje. Pero la Literatura Comparada también permite, a juicio de este mismo autor, el análisis de las relaciones intermediáticas, entendidas como aquellas que se producen entre dos textos dados, siendo al menos uno de los dos no estrictamente lingüístico, es decir, que puede ser visual o, como es el caso, audiovisual. 
La dimensión narrativa de la televisión ha sido analizada muy sucintamente por BARROSO GARCíA (1991: 492), que la ha descrito como una "narrativa de la realidad" o por GoRDILlo RodRíGUEZ (1999), que, en otro trabajo, también se ha aventurado a estudiar las estructuras narrativas del informativo diario de televisión. Sin embargo, la mayor parte de aproximaciones que, de manera creciente, han ido ofreciendo los diversos autores durante estos últimos años se han concentrado en el estudio de productos de ficción (CASCAJOSA ViRINO, 2009). Pero poco importa, a efectos de este trabajo al menos, que la mayor parte de los análisis narratológicos se hayan centrado en este tipo de textos o, como mucho, en aquellos que están en "las fronteras de la ficción" (PIÑERA TARQUE, 2009: 272) como la autobiografía o el film documental. En casos como estos, el pacto pragmático que regula su construcción es el de la ficción, no el de la realidad. En el tipo de texto analizado sucede lo contrario. Y entendemos que ello no tiene consecuencias para el análisis narratológico.

Entendemos, con GARCÍA JIMÉNEZ (1993), que la narratología original no aborda con precisión los problemas suscitados por dos dimensiones fundamentales del relato audiovisual: la pragmática y la poética. Por eso esta investigación es más bien deudora del más ajustado concepto de narrativa audiovisual que propone este mismo autor:

“... ordenación metódica y sistemática de los conocimientos, que permiten descubrir, describir y explicar el sistema, el proceso y los mecanismos de la narratividad de la imagen visual y acústica fundamentalmente, considerada ésta (la narratividad), tanto en su forma como en su funcionamiento..." (GARCíA JiMÉNEZ, 1993: 14)

Este autor se ha esforzado en señalar que la narrativa de la televisión puede no ser equivalente a la del cine, aunque ambas sean de carácter audiovisual y, por supuesto, tengan muchos puntos en común. "Existen [...] unos códigos audiovisuales comunes a diversos medios y unos subcódigos específicos de cada uno de ellos, de tal manera que puede hablarse incluso de diversos géneros de lo audiovisual" (CEBRIÁN HerReROS, 1978: 42). En concreto, como elementos exclusivos de la televisión y ajenos al cine señala dos: la programación y la transmisión en directo (CEBRIÁn HERREROS, 1979: 154). El primero remite a la imposibilidad de transmitir obras aisladas. El segundo, el más útil para este trabajo, es la transmisión en directo. Desde un punto de vista narratológico, este aspecto ayuda a explicar la multiplicidad de voces narrativas presentes en el informativo de televisión. Para este autor el relato directo es "el relato transmitido por televisión en el mismo momento en que se produce el hecho y desde el mismo lugar donde se desarrolla" (CEBRIÁN HERREROs, 1978: 189). En este tipo de situaciones el tiempo narrativo adquiere una dimensión difícil de localizar en otro tipo de relatos, incluido el cinematográfico.

“... para el relato directo el tiempo es un elemento intrínseco. El tiempo en su transcurrir, en su vitalidad, es fugaz y no hay posibilidad de volver sobre él. Cuando se intenta volver al pasado se pierde el presente. Pero aquí cabe destacar un matiz que es privilegio de la televisión. El tiempo de Heráclito no puede volver al pasado. El tiempo del relato televisivo puede volver y a la vez ofrecer el presente. Este es el milagro de la televisión: poder desglosar el tiempo, recordar el pasado y enfrentarlo al presente en su mismo devenir, mediante la simple división de escenas en la pantalla. Este hecho no puede realizarlo el cine, pues nunca podrá recoger el presente" (CEBRIÁN HERRERos, 1978: 190) 
Este trabajo se fija más en el relato -la manera de narrar unos acontecimientosque en la historia -la serie cronológica de los acontecimientos relatados (GAUDREAULT y Jost, 1995: 43)-. La mayoría de las escasas aproximaciones teóricas (MARín, 2003) al informativo de televisión o los manuales (OLIVA y SITJÀ, 1992) lo definen como un formato. Otros, como GordiLlo (1999) o BARROSo (1991: 356) lo consideran, de manera genérica, un discurso. La primera llega incluso a escribir que el telediario es "el discurso emblemático del género informativo en televisión" (GoRDILLO, 1999: 54), es decir, una especie de subgénero. Compartimos la idea de que es un discurso porque en el informativo de televisión existe orden y selección (y una voluntad de coherencia narrativa), que, según CHATMAN (1990: 28), son las principales características del discurso como categoría. Ya desde el punto de vista estrictamente narrativo, CEBRIÁN HERREROS (1978: 279) ha definido el informativo de televisión como una unidad sintagmática yuxtapuesta. Aunque ha centrado su descripción en un informativo muy concreto, entendemos que su análisis es un buen punto de partida para esta investigación:

"El Telediario se inicia siempre con una cabecera de entrada, idéntica para las tres ediciones diarias, con lo cual la persona que está ausente en este momento pueda reconocer el programa por el elemento sonoro. Esta es la misión de toda la sintonía y mucho más en este unidad concreta, ya que se trata de una macrounidad cíclica diaria y, además, de una macrounidad intermitente. Es el ejemplo claro del funcionamiento independiente de los dos canales. Si en algún momento la imagen se interrumpiera, la sintonía identificaría por sí sola el programa.

La narrativa del telediario es siempre sintagmática. Sea cual sea su duración, siempre aparece segmentado, compuesto de microunidades, que a su vez se componen de otras microunidades de rango inferior, y así hasta llegar a la unidad base que es la noticia, con independencia del tratamiento que se le dé. Precisamente estas unidades quedan perfectamente relacionadas en el denominado "minutado" que es una hoja en la cual se establece el orden y las características técnicas de cada noticia. Las noticias se yuxtaponen. Para resaltar esta yuxtaposición con función separadora, cada noticia es ofrecida a través de locutores diferentes. En otros Telediarios todavía se conserva la figura del locutor coordinador de las noticias y que se encarga de darles cierta unidad y continuidad. Pero la diferencia de actantes es sólo a nivel de tono, timbre e intensidad de voz y aspecto físico, pero son muchos más los datos que les unen a nivel actancial.

[...] Algunas microunidades establecen una doble narrativa. Se trata de una narración presentada por un locutor en imagen, mientras en el fondo, gracias a las transparencias y el chroma-key se ofrece la narrativa propia de los acontecimientos. Esta doble narrativa es muy propia de los contenidos informativos para diferenciar precisamente el elemento comentador o narrador y el hecho narrado (1978: 280)"

Una definición más pegada a la práctica profesional es la de Gabriel PÉREZ (2003: 79) para quien un informativo de televisión es, sencillamente, "la manera teórica de agrupar, ordenar y elaborar las informaciones que se producen a lo largo del día". Este autor recuerda algunos aspectos esenciales en la construcción narrativa de un informativo: 
“... la audiencia no admite que la emisión de las noticias se haga en forma de interés decreciente en sentido estricto (de lo más importante a lo menos) porque entonces llegará un momento en el que compruebe que lo que está ofreciendo le empieza a aburrir y termine por desconectar. Tampoco se pueden permitir las noticias mezcladas, haciendo referencia a temas que corresponden a ámbitos informativos distintos: el espectador se siente perdido, cuando, por ejemplo, a una noticia política sigue otra de cultura o un suceso, para pasar a continuación otra vez a la cultura y después a otro suceso. La experiencia dicta que lo razonable es agrupar la emisión en bloques de noticias, en bloques temáticos. De esta forma se asegura el equilibrio en el interés, ya que cada bloque comenzará con la noticia más importante del día en ese ámbito. Por otra parte, la agrupación de noticias que hacen referencia al mismo núcleo de interés evita que el espectador se despiste, se pierda temas. [...] parecía claro que debía existir algún elemento que permitiera la transición entre bloques, y fuera percibido así por la audiencia. De esta manera, aparecieron las ráfagas de separación con un fondo sonoro neutro, y, al tiempo, con capacidad suficiente para alertar al oído sobre lo que venía a continuación; algo que se identificara como perteneciente a un ámbito temático diferente, aunque esta percepción no fuese del todo consciente”. (PÉREZ, 2003; 80)

\section{Metodología y objeto del análisis}

La muestra analizada comprende varios informativos emitidos entre junio de 2006, cuando empezaron las emisiones regulares, y septiembre-octubre de 2010, cuando se producen las últimas modificaciones en su estructura hasta el momento en que comienza la redacción de este trabajo. En concreto, se estudian 19 TPA Noticias. Todos corresponden a la edición de las 20.30 de lunes a viernes, la primera que se puso en antena. De la muestra seleccionada, sólo una de las emisiones no se ha incluido en el análisis: la correspondiente al 4 de octubre de 2010, que sólo duró cinco minutos como consecuencia de la alteración de la parrilla propiciada por la emisión de un partido de fútbol. La sustancial modificación de su estructura como consecuencia de estas circunstancias ha desvirtuado su utilidad para este análisis.

La muestra se ha extraído de cuatro momentos en los que existieron modificaciones sustanciales en la estructura de la narración. Así, se han seleccionado los cinco primeros informativos de la edición de las 20.30 de lunes a viernes, los correspondientes a los días 9, 12, 13, 14 y 15 de junio de 2006. No se han incluido los de los días 10 y 11 por haber sido emitidos un sábado y un domingo, respectivamente. El segundo cambio se operó a principios de 2007. La información deportiva pasó a integrarse en la estructura del TPA Noticias y desaparecieron las parejas de presentadores. Los primeros informativos de la nueva etapa fueron emitidos los días $12,13,14,15$ y 16 de enero de 2007. Hasta los últimos días de septiembre no volvió a haber modificaciones de importancia. Fue entonces cuando la estructura experimenta cambios en los sumarios, incorpora la información del tiempo, y ofrece un sumario de salida, como novedades más destacadas. El nuevo planteamiento se pudo ver los días 25, 28, 29 de septiembre y el 1 de octubre de 2010. Una vez más, de esta muestra excluimos los que aparecieron en fin de semana, los correspondientes a los días 26 y 27 y el del día 30, que duró sólo seis minutos. Finalmente, en octubre de 2010 TPA Noticias experimenta el último cambio sustancial hasta el momento de la redacción de este trabajo. La modificación más perceptible en esta nueva etapa es la retirada de la información depor- 
tiva, si bien esta alteración no tendrá como consecuencia la vuelta a la estructura original sino la formulación de una propuesta nueva, que se pudo ver durante la primera semana del mes de octubre de 2010, en concreto a partir de los días 5, 6, 7 y 8, dado que el lunes 4 la emisión fue reducida. En definitiva, la muestra seleccionada para su análisis corresponde a 5 días de junio de 2006 (9, 12, 13, 14 y 15); 5 días de enero de 2007 (12, 13, 14, 15 y 16); 4 días de septiembre de 2009 (25, 28 y 29. El día 30 no fue seleccionado porque su naturaleza reducida desvirtuaba el análisis); y 5 días de octubre de $2010(1,5,6,7$ y 8 . El día 4 no fue seleccionado porque su naturaleza reducida desvirtuaba el análisis)

Se ha procedido a una aproximación eminentemente fenomenológica. El autor ha visionado cada uno de esos textos con las herramientas de la narratología en la mano. Al modo de Vladimir Propp con los cuentos de hadas rusos, la investigación se ha fijado en que existe un "código implícito en el corpus de cada historia, un código que los lectores [...] conocen y esperan" (CHATMAN, 1990: 95). Para el texto objeto de análisis la metodología de TODOROV sobre el Decamerón sí puede resultar de utilidad porque nos encontramos con una "repetición a gran escala, como en la lengua o el foklore" (ChATMAN, 1990: 96). Lo que, siguiendo a CHATMAN, resultaría mecanicista a la hora de analizar otro tipo de discursos, sirve a esta investigación. En cada una de las emisiones diarias del informativo se encuentran las suficientes recurrencias como para que esta metodología sea de utilidad. Según CHATMAN (1990: 87), "la recurrencia de relaciones es necesaria si hay que identificar una estructura narrativa. [...] No se puede hablar de la estructura de un relato si nos limitamos únicamente a ese relato".

\section{La voz narrativa}

En todo análisis narratológico es preciso determinar la naturaleza de las instancias enunciadoras. Pero no todas las instancias enunciadoras del informativo de televisión encajan en las taxonomías existentes. Según la convención, el narrador es un "ser de papel o de celuloide" (GARCÍA JiMÉNEZ, 1993: 85); mientras que únicamente el lector concreto habita en el mundo físico y tiene biografía, si bien existen excepciones, como La familia de Pascual Duarte, en la que el narrador se dirige un lector concreto que no habita el mundo real. La excepción podría asimismo aplicarse también a la instancia del narrador, dado que, como demuestra el tipo de texto analizado, puede también habitar el mundo real. De hecho, esta circunstancia acaba resultando esencial para que el pacto de verosimilitud funcione y, en consecuencia, para establecer la deseada comunicación con el lector.

Según Chatman (1990: 165-166), "el punto de vista está en la historia (cuando es del personaje), pero la voz narrativa siempre está fuera, en el discurso". En teoría, aunque el narrador de un informativo de televisión es el presentador y los sucesivos redactores, la estrategia narrativa se esfuerza por aparentar que el punto de vista es el de los personajes. De ahí el interés por incorporar su testimonio en estilo directo por medio de los totales ${ }^{1}$ (BANDRÉs et al, 2000: 273). La afirmación de CHATMAN, por otra

1 Un total es "un testimonio limpio de una o varias personas sobre un tema concreto en una información para televisión. Equivale a una declaración” (BANDRÉs et al, 2000: 273) 
parte, nos obliga a preguntarnos si el narrador, y los subnarradores, son homodiegéticos o heterodiegéticos. Según este autor (1990: 166), "cuando se relata una percepción [...] se presupone necesariamente otro acto de «observación» con un punto de vista independiente, es decir, el del narrador". Pero el narrador, según CHATMAN, ya no percibe, sino que concibe. Y esta es la distinción clave:

“... El narrador totalmente externo presenta una visión aún más puramente conceptual. Nunca estuvo en el mundo de la obra: el tiempo del discurso no es una extensión posterior del tiempo de la historia. No «percibió» en el mismo sentido directo o diegético que lo hizo cualquier personaje. Literalmente hablando, no puede haber «visto» nada en ese otro mundo" (ChatMan, 1990: 66-167)

Pero no sucede así con el narrador de un informativo de televisión. En este tipo de narración, el tiempo del discurso sí es una extensión posterior del tiempo de la historia, aunque sólo sea porque es una premisa fundamental del pacto de veracidad que el narrador sí haya visto todo de ese otro mundo antes de relatarlo. El discurso narrativo de un informativo de televisión rechaza la existencia de concepciones. Postula que todo lo narrado son percepciones. Esta hipótesis cancela la distinción que formula CHATMAN entre, por una parte, un narrador de segundo orden, heterodiegético, que elabora conceptos sobre la historia, y un personaje de primer orden que elabora conceptos dentro de la historia. Esta identificación elimina posibles disociaciones más habituales en la literatura. Chatman pone como ejemplo The Secret Agent, de Conrad. En él, al narrador no le importa mostrar antipatía por el personaje. En principio, esto no sucede en un informativo de televisión ideal. En este tipo de narraciones, y salvo en aquellas más claramente editorializantes, resulta poco habitual la disparidad entre el punto de vista del personaje y la expresión del narrador.

Que el presentador de un informativo de televisión, además del principal narrador, es también un personaje lo demuestra la utilización de una de las técnicas para destacar el punto de vista de un personaje que, según CHATMAN recuerda, ofrece el cine:

"La otra convención (o «montaje») usa una simple combinación de cortes: si en el plano primero el personaje está mirando hacia fuera de la pantalla, hacia la derecha o la izquierda, delante o detrás, y luego sigue un corte y se pasa a otra imagen dentro de su campo visual, suponemos que realmente ha visto eso, desde ese punto de vista perceptivo, y nosotros lo hemos visto con él (o viceversa: nosotros podemos verlo primero y luego haber un corte y pasar al personaje que lo está mirando)" (CHATMAN, 1990: 171)

De vez en cuando, al terminar de introducir un vídeo, el presentador dirige la mirada hacia un lugar situado fuera del encuadre, al monitor en el que se proyecta el vídeo que acaba de introducir. Con este sencillo gesto, refuerza la continuidad entre lo que acaba de relatar y lo que el espectador está a punto de ver. Pero, además, y desde un punto de vista estrictamente narratológico, incrementa la identificación entre narrador y narratario al recordarle que está viendo lo que sucede a través de los ojos de quien está relatando la historia, a través de un personaje, el narrador-presentador en este caso.

En el plano de la expresión, en el del discurso, CHATMAN (1990: 157) ha distinguido dos tipos de enunciados narrativos, "dependiendo de si el predicado narrativo profundo (no el predicado lingüístico de la superficie) está en el modo de la existencia 
(ES) o de la acción (HACE)". Esta distinción le resulta útil para averiguar si el enunciado es presentado al público directamente o a través de una mediatización. La presentación directa sería la mimesis de Platón y la narración mediatizada la diégesis. Si en la primera se muestra, en la segunda se cuenta. Y si se cuenta es que alguien lo cuenta y que, por lo tanto, existe una voz narrativa. Según este autor, se puede establecer una tipología de la voz narrativa en función de la presencia del narrador. Afirma que la pura mímesis es una ilusión y que, por lo tanto, de lo que se trata es de averiguar cómo se edifica la convención según la cual el espectador o lector cree que está asistiendo directamente a la escena. La clave está, asegura, en la restricción de los tipos de enunciados por parte del autor.

Para elaborar una taxonomía de esas restricciones lo primero que hace es dejar claro que el autor y el narrador pueden no ser la misma persona. Distingue, además, entre autor real y autor implícito. Sobre el autor implícito explica CHATMAN:

“... reconstruido por el lector a partir de la narración. No es el narrador, sino más bien el principio que inventó el narrador, junto con todo lo demás en la narración, que amontonó las cartas de esta manera especial, hizo que estas cosas sucedieran a estos personajes en estas palabras o imágenes. A diferencia del narrador, el autor implícito no puede contarnos nada. Él, o mejor dicho, ello no tiene voz, ni medios de comunicación directos. Nos instruye silenciosamente, a través del diseño general..." (CHATMAN, 1990: 159).

Asegura también que siempre hay un autor implícito, pero que podrían haber más de un autor real, como sucede en las baladas populares o en un programa de televisión. El autor real del texto analizado en este trabajo es múltiple: redactores, editores, realizadores, productores, presentadores, director de informativos... Pero, al final de la emisión, en el caso particular analizado, sólo firman el editor, el realizador y el productor. Aún así, a pesar de esta reivindicación de autoría, el autor implícito es, muy probablemente, el presentador porque, en el caso particular de un informativo de televisión, el espectador acostumbra a atribuirle a él toda la autoría.

Otra forma de determinar la naturaleza de un narrador la proporciona la tipología de Gérard GENETTE (1998) que los clasifica en autodiegéticos, homodiegéticos y heterodiegéticos. El primero es aquel que relata sus propias experiencias como personaje central de la historia. En el segundo de los casos, el narrador obtiene la información que cuenta en sus historias de su participación en la diégesis. En el tercero, finalmente, el narrador cuenta una historia en la que no se implica como personaje. El narrador de un informativo de televisión no es un narrador heterodiegético, si bien el primero comparte con el segundo una serie de rasgos: ambos se sitúan en un momento posterior a la historia que cuentan -aunque el primero, en ocasiones como los directos, opera de otra forma- y los dos utilizan el sumario. Además, coinciden en usar, por lo general, la tercera persona. Según GENETTE, sin embargo, el narrador heterodiegético se mantiene en el anonimato. Y este no es el caso del narrador de un informativo de televisión. Este último tampoco puede ser el narrador autodiegético porque, aunque también comparten algunos rasgos, el recurso de este último a la modalidad narrativa del monólogo interior los distancia.

El narrador de un informativo de televisión, en fin, tiene más puntos de coincidencia con el narrador homodiegético: "Es una figura intermedia entre el narrador au- 
todiegético y el heterodiegético. Se diferencia de aquél en que, siendo personaje como él, no es el personaje central de la historia. Se diferencia del heterodiegético en que participa de la diégesis, y el conocimiento de aquello que cuenta es, por tanto, un conocimiento directo" (GARCíA JIMÉNEZ, 1993: 116)

En la narrativa audiovisual, la voz permite definir el lugar del narrador explícito en relación a la diégesis. No es necesario, por lo tanto, observar la persona gramatical como sucede con la novela. El presentador es un narrador homodiegético dado que su voz procede de uno de los personajes visualizados. No determina su situación, por lo tanto, el empleo de una u otra persona gramatical, el uso del Yo o de el El que sirve al lector para ubicar al narrador en la novela. En la narración audiovisual resulta suficiente el timbre de la voz. De todas maneras, tanto el presentador como los locutores refuerzan esa dimensión homodiegética recurriendo, no a la primera persona del singular, pero sí a la del plural en numerosas ocasiones.

El uso de la primera persona será recurrente a la hora de narrar lo que prometen estos cebos. De hecho, el presentador, en su turno, también hace uso de ella. El uso de la primera persona en los textos narrativos ha estado históricamente asociada a la búsqueda de una mayor identificación entre el narrador y el narratario. Su uso en estos cebos, y no, por ejemplo, en el sumario, revela la intención del autor de utilizarlos para lograr un mayor acercamiento al público.

En el texto audiovisual existen tres tipos de voz: la que está in, la que se pronuncia en el propio campo; la voz off, la que emerge de algún lugar fuera del encuadre; y la voz over, que es la que adopta un locutor invisible cuando se encuentra en un espacio y un tiempo que no son exactamente los que representan las imágenes de la pantalla, según la definición de Kozloff (1988) que recogen GAUDREAUlT y Jost (1995: 82). Esta última es la más presente en un informativo de televisión y la menos habitual en el relato cinematográfico, que suele recurrir a voces in de manera prioritaria para hacer avanzar la narración. En un noticiario, sin embargo, la mayor parte de la narración descansa sobre un número variable de voces over que ofrecen distintos microrrelatos que va trenzando el presentador.

En el primero de los informativos (09-06-06), la mayor parte de las voces que aparecen en las microhistorias están en over. Sólo en cuatro de ellas la fuente aparece en pantalla: el primero, centrado en la sequía en el campo asturiano; el segundo, en el que se denuncian los problemas de los lagos de Covadonga; el dedicado a la feria de Vegadeo; y el que informa sobre el rodaje de la película El Orfanato. En estos tres, el locutor aparece durante unos segundos en pantalla, de manera que la voz pasa de over a in, de forma que interviene en la diégesis en forma de presencial. En los otros once nada indica que el narrador participe o haya participado de lo que se muestra en pantalla, con la excepción de dos de las historias narradas, la centrada en la desaparición de una persona durante la dictadura de Videla en Argentina y la que muestra una exposición de fotografía en Gijón. En estos dos casos, el narrador llega a aparecer en pantalla, pero de una manera tan poco enfática que el espectador no tiene porqué relacionar la voz que está oyendo con una de las personas que aparece en la diégesis. La voz de estos subnarradores puede, por lo tanto, manifestarse de diferentes formas, incluso, como veremos, en off, que es lo que sucede en los directos, sin embargo, en 
el informativo analizado esta multiplicidad de manifestaciones desaparecerá paulatinamente. Con el paso de los años, estos locutores aparecerán más habitualmente en over, perdiendo riqueza la narración.

La voz del narrador principal, sin embargo, mantendrá siempre esa multiplicidad de manifestaciones. A veces estará en in, como cuando introduce una información que alguien va narrar en over, es decir, cuando lee una entradilla ${ }^{2}$. Pero otras veces su voz permanecerá en over, como cuando relata una información pero es invisible y de repente está situado en un espacio y un tiempo que no son los que representan las imágenes, lo que en el argot televisivo se conoce como $\operatorname{colas}^{3}$. Otras veces no sólo es el presentador el que está en in, sino también algún redactor que relata un hecho en directo. Más frecuentemente, sin embargo, el in se reserva para los protagonistas de las narraciones, que, siempre que es posible, intervienen en los relatos en estilo directo, son los denominados totales. La voz en off en un noticiario queda para las narraciones de acontecimientos en directo. La fuente de la voz no está en el encuadre pero sí en un espacio contiguo. No puede ser over porque, siguiendo la definición de Kozloff ${ }^{4}$, aunque el locutor es invisible, tal vez no el espacio, pero sí el tiempo coincide con el que ofrece simultáneamente la pantalla. Los intercambios entre las voces de los personajes ofrecen, pues, múltiples combinaciones, que no son exclusivas del discurso de un noticiario sino que se encuentran presentes también en los relatos cinematográficos (GAUdREAUlt y Jost, 1995: 82-85). La mirada a cámara puede deberse a la voluntad de vincular al espectador a la diégesis propuesta. Si bien al principio fue frecuente en el cine, desapareció cuando la intención de contar historias lineales exigió la creación de un mundo diegético autónomo. (GAUDREAULt y Jost, 1995: 53)

\section{Conclusiones}

El narrador de un informativo de televisión ejerce más desde una omnisciencia injerente, que desde la neutralidad. Es, además, homodiegético, dado que su voz procede de uno de los personajes visualizados. No determina su situación, por lo tanto, no necesita el empleo de una u otra persona gramatical (la primera o la tercera impersonal) como sucede para ubicar al narrador en una novela. En la narración audiovisual resulta suficiente el timbre de la voz. De todas maneras, tanto el presentador como los locutores refuerzan esa dimensión homodiegética recurriendo, no a la primera persona del singular, pero sí a la del plural en numerosas ocasiones. En el texto audiovisual existen tres tipos de voz: la que está in, que se pronuncia en el propio campo; la voz off, la que emerge de algún lugar fuera del encuadre; y la voz over, que es la que adopta

2 Según BANDRÉS et al (2000: 226), la “introducción de la noticia que lee el locutor desde plató".

3 Según BANDRÉs et al (2000: 262), "las imágenes con sonido ambiente que son comentadas en directo por el presentador".

4 “... enunciados orales [que] vehiculan cualquier porción del relato, pronunciados por un locutor invisible, situado en un espacio y un tiempo que no sean los que se presentan simultáneamente a las imágenes que vemos en la pantalla” (Kozlof, 1988, en GAUDREAULT y JOST, 1995: 82) 
un locutor invisible cuando se encuentra en un espacio y un tiempo que no son exactamente los que representan las imágenes de la pantalla. Esta última es la más presente en un informativo de televisión y la menos habitual en el relato cinematográfico, que suele recurrir a voces in de manera prioritaria para hacer avanzar la narración. En un noticiario, sin embargo, la mayor parte de la narración descansa sobre un número variable de voces over que ofrecen distintos microrrelatos que va trenzando el presentador. La voz del narrador principal mantendrá siempre esa multiplicidad de manifestaciones.

En el caso del narrador (y subnarradores) de un informativo de televisión no se puede hablar ni de mímesis pura ni de diégesis pura. Existen transcripciones directas de lo que dice un personaje, los llamados totales, una práctica que remite a la primera de las actitudes narrativas, la mímesis; pero también señales tales como pensó o dijo indican una presencia narrativa. Es en este tipo de alternancias, entre otros aspectos, donde se identifica con mayor precisión la singularidad narrativa del informativo de televisión, tanto si se lo compara con el resto de formas de relatar, incluyendo las escriturísticas, como si se repara únicamente en las de estricta naturaleza audiovisual. La tenue frontera entre mímesis y diégesis en este tipo de textos se aprecia asimismo en otro tipo de fórmulas narrativas, aquellas que, aprovechándose de las posibilidades del relato doble, ofrecen lo que de mímesis tiene un testimonio en su manifestación puramente visual, mientras la voz continúa siendo la del narrador.

En lo relativo a la enunciación, el discurso del noticiario se encuentra más próximo al cine clásico que al moderno, dado que su intención es más bien borrar, ocultar la influencia condicionante del gran imaginador. Para el narratario de un informativo de televisión el autor es el narrador-presentador. Y, sin embargo, por encima de los narradores, también existe un meganarrador (editor) que se esfuerza, por otra parte, en permanecer oculto, porque una premisa fundamental del pacto de verosimilitud que sustenta relatos como el analizado es que no existe un autor implícito, que lo que se muestra es la realidad tal y como acontece. Durante la emisión de cada noticia desaparece el narrador principal y quien ocupa todos los canales es el subnarrador. Porque en el caso de un texto como el analizado, además del narrador presentador, existen una serie de subnarradores que son usuarios del lenguaje audiovisual, los redactores, que, ellos sí, tienen la potestad de transformar lo que relatan en imagen. En el informativo de televisión, el personaje-narrador-presentador habla en imágenes, pero también lo hacen los personajes-subnarradores-redactores. Cada uno de estos narradores es usuario, por tanto, del lenguaje audiovisual. De hecho, esta multiplicidad de usuarios contribuye a cimentar el pacto de verosimilitud que sustenta todo el relato. Evidenciar el carácter de obra colectiva de un informativo de televisión ayuda a explicar por qué se tiene acceso a los aspectos más diversos de la realidad.

Según la convención, el narrador es un ser de papel o de celuloide. Una excepción, sin embargo, podría aplicarse al narrador del informativo de televisión, dado que, como demuestra el tipo de texto analizado, puede también habitar el mundo real. De hecho, esta circunstancia acaba resultando esencial para que el pacto de verosimilitud funcione y, en consecuencia, para establecer la deseada comunicación con el lector. Asimismo, en el tipo de texto analizado también se observa un interés por re- 
ducir la distancia con el espectador. La mirada a cámara del narrador, el uso de deícticos que lo implican en la narración, son técnicas que tienen por objeto reducir la barrera que representa la pantalla del televisor.

\section{Referencias bibliográficas}

BANDRÉS, Elena; GARCÍA AVILÉS, José A.; PÉREZ, Gabriel y PÉREZ, Javier (2000): El periodismo en la televisión digital. Barcelona, Paidós.

BARROSO, Jaime (1991): La producción de la información de actualidad: forma y formato de la noticia. Madrid, Editorial de la Universidad Complutense.

CEBRIÁN HERREROS, Mariano (1978): Introducción al lenguaje de la televisión. Una perspectiva semiótica. Madrid, Ediciones Pirámide.

CHATMAN, Seymour (1990): Historia y discurso: la estructura narrativa en la novela y en el cine. Madrid, Taurus.

CHILLÓN, Albert (1994): "L'estudi de les relacions entre periodisme y literatura per mitjà del comparatisme periodístico-literari". Anàlisi. Quaderns de comunicació y cultura. $\mathrm{N}^{\circ} 16$. Barcelona, UAB. Pgs 123-150.

GARCÍA JIMÉNEZ, Jesús (1993): Narrativa audiovisual. Madrid, Cátedra.

GAUDREAULT, André y JOST, François (1995): El relato cinematográfico. Barcelona, Paidós Comunicación.

GENETTE, Gérard (1998): Nuevo discurso del relato. Madrid, Cátedra.

GORDILLO, Inmaculada (1999): Informativos en Andalucía. Estructuras narrativas del informativo diario en televisión. Granada, Junta de Andalucía, Consejería de Cultura.

PÉREZ, Gabriel (2003): Curso básico de periodismo audiovisual. Pamplona, Eunsa.

PIÑERA TARQUE, Ismael (2009): Mundos narrativos. Relato literario y relato filmico. Kassel, Edition Reichenberger.

PROPP, Vladimir (1971): Morfología del cuento. Madrid, Cátedra.

TODOROV, Tzvetan (1991): Los géneros del discurso. Caracas, Monte Ávila Latinoamericana Editores. 